\title{
Factors Affecting Consumers Behavior of Coventry University Students Towards Fast-Fashion Industry
}

\section{Erini Junita Sari ${ }^{1}$, Hanifah $^{2}$}

1STIE Indonesia, Banjarmasin, Indonesia, $\square$ (e-mail) erini@stiei-kayutangi-bjm.ac.id

${ }^{2}$ STIE Indonesia, Banjarmasin, Indonesia, $\bowtie$ (e-mail) hanifah@stiei-kayutangi-bjm.ac.id

\begin{abstract}
Despite of its rapid growth, fast fashion industry is still considered as an under-researched field. Researches related to fast fashion are rare to be found, both in academic and marketing aspects. This research is conducted to serve the purpose of addressing the characteristics of consumer behavior of Coventry University students in fast fashion industry at Coventry, to analyze how the general and conventional theories of consumer behavior apply to the consumer behavior of fast fashion, and to identify the factors influencing consumer behavior of Coventry University students in fast fashion industry at Coventry. The analyses are based on the combination of the general consumer behavior theories, empirical findings from questionnaires conducted at Coventry University, and studies of fashion and fast fashion. There are 2 main findings of this study. Gender has no influence on students' purchasing decisions. Whereas, culture has an influence on students' purchasing decisions in Conventry University. The findings of this study are further developed into marketing recommendations and offers of idea for further research.
\end{abstract}

Keywords: consumer behaviors, purchasing decisions, cultural factor, gender, and fastfashion industry

\section{Introduction}

By identifying and understanding the factors, fast-fashion brands could develop an efficient marketing message (Unique Value Proposition) and good advertising campaigns that fit the target market's demands and perceptions. Fast-fashion industry is also strongly related to e-commerce, as the result of digitalization of the world. Many brands promote and sell their products through their websites or online shopping mall. Many customer engagements are conducted online, as people have become more mobile and busier. They find it more convenient to shop online. More options are offered by fastfashion brands through their online websites. This digitalization of fashion industry has also become a part of the concern in consumer behavior.

Currently, there are not so many existing researches about consumer behavior in fashion industry available. However, there are some researches that were conducted and able to contribute in fashion industry, for example the book about consumer behavior in fashion by Michael R. Solomon and Nancy J. Rabolt in 2004 (Solomon \& Rabolt, 2009). Through their book, Solomon and Rabolt provide a comprehensive analysis about the consumer behavior in fashion industry nowadays. However, researches or studies related to the fast fashion industry are considered as extremely rare. Fast fashion industry gets too little attention, despite of the fact that this part of fashion needs to be separated from fashion theories in general. The fast fashion industry is considered as a new growing market; thus, its own characteristics are ignored although there are many differences existing between fast fashion and conventional fashion (Wang, 2010, 4).

This research is expected to contribute on finding the reasons of consumer's different preferences in fast-fashion industry and what influences the purchasing decision. This research is also expected to separate consumer behavior pattern of fast fashion industry from the conventional fashion industry. 
The lack of knowledge about the consumer behavior in fast fashion industry might restrict the growth of brands expanding in fast fashion industry, as they treat the market of fast fashion in the same way they do with the conventional fashion. This is considered as one of biggest issues that hinders the development of fast fashion industry. It is still vague, whether gender and cultural and social class factors can influence consumer behavior in making purchasing decision or not in fast fashion industry.

There are two objectives of this research, as follows. First, analyzing the influence of gender towards consumer behavior of Coventry university students in fast-fashion industry. Second, analyzing the influence of cultural factor towards consumer behavior of coventry university students in fast fashion industry.

Consumer behavior is a term used to define the buying characteristics of the consumer. Consumer behavior can be identified through their actions and decision making in purchasing. Various consumers portray various types of buying behavior. There are many factors, specifications, and characteristics that influence an individual's personality and the individual in his decision making process, purchasing behavior, shopping habits, his choice of brand and outlet.

Consumer behavior also portrays a complexity. The consumers usually have their own buying patterns through time within a market where multiple brands exist. (Lawrence, 1966: 216). Many studies related to the consumer behavior had attempted to find the understanding of the reasons a consumer purchase a particular product and the factors that influence consumer's decision in purchasing.

The phenomenon of globalization has changed people's behavior and the way they conduct business. It is highly suggested by the researchers to the marketers to thoroughly analyze the internal reasons that could motivate customers to respond positively to the given marketing stimuli, and the way they make choices. According to Rossiter and Foxall (2008), there are three known causes that affect behaviour directly, which are (a) initiating stimuli; (b) momentary motivation or 'drive' level; (c) habits, which include beliefs, attitudes, and values; and (d) external incentives. In addition to this, social class is associated to the third cause, the habits (Rossiter, 2012, 89).

According to Hofstede (1948), a nation's culture has been proved to have a significant impact on the values and attitudes of an individual. A nation's culture is also known as important and to have a significant influence on the decision-making style of a consumer (Leo, Bennet, \&Hartel, 2005).

Culture is a powerful component in shaping human behavior, as it consists of set of common patterns of behavior that are delivered and maintained by the members of a particular environment and society through various purposes. (Arnolds \& Thompson, 2005). There is hardly any aspect of life that cultural values do not affect. The cultural value system includes cultural elements that people have in common with the group to which they belong, as well as idiosyncratic values unique to that individual (Luna \& Gupta, 2001). These values most likely affect the behavior of the consumer and determine the choice of criteria followed by the consumers. These values are socialized into a particular group and passed on to the next generation (Triandis, 1995). As a result, values are carried on over time and, therefore, may have a certain influence on the way consumers behave. Luna \& Gupta (2011) also stated that the values carried on from the previous generation could further influence the consumer decisions, and affect consumers in deciding which basic everyday products to buy, or which major and important products to buy.

For a brand, it is important to understand and take into account the cultural factors inherent to each market or to each situation in order to adapt its product and its marketing strategy to the market. As these factors will play a role in shaping the perception, habits, behavior or expectations of the products. Mourali et al., (2005) has previously mentioned similar statement, that on a daily basis, an individual will 
be influenced by his family, his friends, his culture, his environment, and his society, that will lead to the shaping of the values, preferences, and common behaviors to their own culture.

Gender is also considered as one of the big factors that influence the consumer behavior in decision making. Because, the consumption behaviors of the two genders heavily reflect the differences between male and female in expectation, want, need, life-style, just to name these (Akturan, 2009:66). This statement refers to the social roles and responsibilities of male and female, the expectations towards the characteristics of each gender, natural tendencies and expected behaviors of both genders (femininity and masculinity) that are learned, altered, and varied trough time within and among cultures. Mitchell and Walsh (2004) stated that men and women desired different products and it is common for them to own different ways in liking and obtaining these. However, the clear differences between both genders are often not caused by genetic factors, but influenced by the cultural variations as well (Teather, 1995).

It is stated by Solomon (2010), that sexual identity is a crucial part of consumer's self-image. Both of the genders believe that there will be no conflict with their culture regarding the way they behave or consume. Nevertheless, as the time goes by and the culture changes, the gender roles will likely to change as well. However, it is still not certain whether different gender has different consumption once there are changes in time and the culture. Thus, many marketers have attempted to further research on gender as factor influencing the consumer behavior, in order to find out the differences and similarities in consuming between the two genders.

Research states that shopping is likely to be an exciting activity for women, rather than to men. The female consumers are likely to feel more independent in shopping. Female consumers recognize shopping as a social need, whereas the male consumers pay more attention to the importance of the main product function instead of its secondary function.

Since its early age, the apparel industry in the UK has always been distinguished by the high number of dominance by the large retailers with an unalterable supply chains (Hines and Bruce 2001). Around the 1990s, the UK's apparel retailers and manufactures saw the pressure in the market from the price set up by the big players. In order to compete with that, the smaller UK retailers such as New Look and George moved their sourcing of products and labors to the Far East to gain a low-cost advantage. However, this action caused a complexity in their supply chains due to the geographical distance, which led the retailers to do alternative practices to cope up with the downside of sourcing in Far East, such as Just-In-Time (JIT), Computer Integrated Manufacturing (CIM), Total Quality Management (TQM) in manufacturing to cut short the supply lines and to initiate a quicker response in the market (Bruce, Daly, and Towers 2004). Due to these practices, the UK retailers are able to provide an increased variety of fashion choices to their customers, while still keeping the low-cost mind in production.

As an addition, a mid-season purchasing is added to follow up on the previous two-season calendars, that rose the providing of high fashion at a low price similar to the price of the "throw away market". The fast fashion that was once called as the "throw away market" has grown into its very own trend and norm (Tokatli, Wrigley, and Kizilgun, 2008). In sum, the concerted fashion market in the UK has developed a trend of gaining competitive advantage and market share by emphasizing on speed in production in street fashion (Birtwistle and Freathey, 1998).

Nowadays, due to the fast movement of information and trend, especially digitally, consumers are able to have the ability to get more options in purchasing which leads them to shop often (Hoffman 2007). The consumer market is broken into different terms based on the patterns of the consumption. With such progress, it is necessary for the researches to pinpoint the whole range of consumer behavior towards fast fashion. There are changes happening in lifestyle caused by the sociocultural factors and a desire for uniqueness, and these changes force the fashion retailers to innovate their products frequently to stay 
distinguished in the growing competition in the market (Sproles and Burns, 1994). The frequent, varied demands of the consumers have affected the forecasting process and the planning of the product is shifting towards the replication of well-known designs and styles from fashion magazines and fashion shows in small amounts more frequently (Christopher, Lowson, and Peck, 2004).

The younger generation would prefer a higher amount of low-quality, cheap, and fashionable clothes (Crewe and Davenport 1992). The conservative consumers view the fast fashion as a 'waste', because instead of buying high quality clothes to meet the expectation, the fast fashion buyers prefer to buy multiple low quality clothes and later throw them away once the styles are outdated (Sydney 2008).

Commonly, the literatures on fast fashion industry point out different aspects in managing the supply chain, while also providing the theory of supply chain in order to improve the business model of fashion retailers. However, it is rare to see studies that addressed the fast-fashion as a consumer-driven approach, leaving this area under-researched.

Based on the description above, the research hypotheses can be formulated as follows:

$\mathrm{H}_{1}$ There is a significant relationship between gender and students' purchasing decision in fast-fashion industry at Coventry

$\mathrm{H}_{2}$ There is a significant relationship between cultural factor and students' decision in fast-fashion industry at Coventry

There are two hypotheses generated in this project, and using the questionnaires, the researcher tested on the research questions against the theories of consumer behavior in fast-fashion industry. This project used offline questionnaires to collect the primary data. The questionnaire consisted of twenty-one questions related to fast-fashion industry in the UK, namely, H\&M, New Look, and TopShop/Topman.

The questionnaires were given out to the respondents in order to know the point of view of the customers towards the fast-fashion industry in Coventry. The target respondents were the Coventry Students from different countries, faculties, and degrees. Eighty questionnaires were spread out to Coventry University students at The Hub. This is considered as a useful method to investigate the different patterns of consumer behavior of Coventry Students in fast-fashion industry at Coventry, and the factors that influence the purchasing decisions.

This project used SPSS for data analysis, in order to simplify the process of data input. SPSS was also used to check on the data validity, and the significant relationships between the two Independent Variables and the Dependent Variables of this research. The type of sample in this research was random sampling, where there was no prior knowledge about the respondents' specific countries of origin, age, and any other information known by the researcher. The significance of the 21 questions in the questionnaire was analyzed using Chi-square and Mann-Whitney in SPSS. The questionnaire was separated into two parts, the first part is consisted of the questions about general information of the researcher (age, university/education, nationality, and gender) and the second part is consisted of the main questions. There are 20 nationalities involved in this data collection through questionnaires (Greek, Indonesian, Chinese, South Korean, Pakistan, Indian, British, Romanian, Bulgarian, German, Srilankan, Vietnamese, Lithuanian, Saudi Arabian, Latvian, French, Belgian, Thai, Hungarian, and Dutch). The project took 3 months to be completed.

The theoretical framework of this research is shown in Figure 1. 
Independent Variable

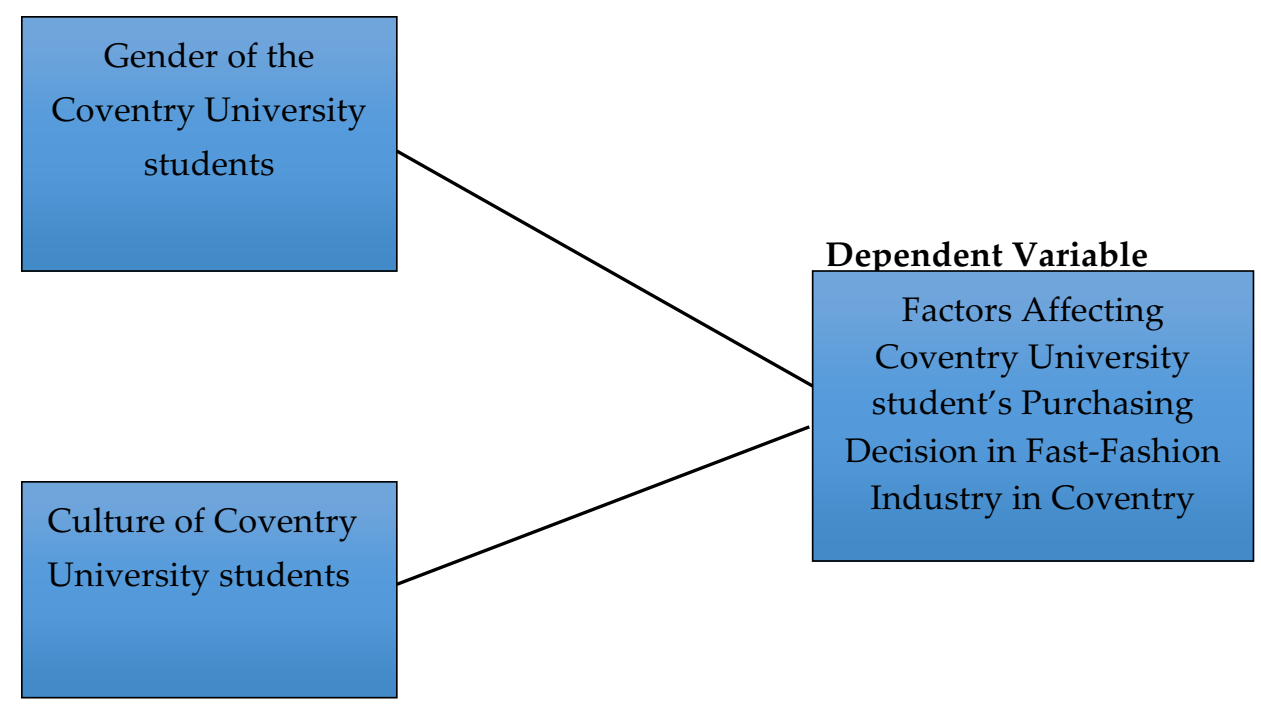

Figure 1 The research hypotheses

\section{Results and Discussions}

Gender is one of the main factors that influence the purchasing decision, especially in fast-fashion industry. There is a significant relationship $(\mathrm{p}=0.035)$ between gender and the respondents' fashion style as shown in Table 1. The findings show that each gender has its own preference in fashion style.

Table 1 Gender as Factor Influencing the Purchasing Decision

\begin{tabular}{lccc}
\hline & Value & df & Asymp. Sig. (2-sided) \\
\hline Pearson Chi-Square & $15.044^{\mathrm{a}}$ & 7 & 0.035 \\
\hline N of Valid Cases & 80 & & \\
\hline
\end{tabular}

According to Akturan $(2009,66)$, gender is one of the determining factors in decision making since the consumption behavior of both genders heavily based on the differences between male and female expectation, want, need and life-style, just to name these.

In terms of brand preference, there are also differences between both genders. Table 2 shows that there is a significant relationship ( $\mathrm{p}=0.024)$ between gender and the "brands that the respondents choose". This difference in brand preference is influenced by the natural difference in characteristics of both genders. Mitchell and Walsh (2004) stated that men and women desired different products and it is common for them to own different ways in liking and obtaining these. According to Chea (2011), men consider price, quality, and selection of the products as the main criteria when they are deciding which stores they should go to.

Table 2 Gender as Factor Influencing gender and the brands that the respondents choose

\begin{tabular}{lccc}
\hline & Value & df & Asymp. Sig. (2-sided) \\
\hline Pearson Chi-Square & $7.442^{a}$ & 2 & 0.024 \\
\hline N of Valid Cases & 80 & & \\
\hline
\end{tabular}

Table 3 shows further findings that there is a significant relationship $(p=0.002)$ between gender and each option of "the feeling the respondents feel while shopping in fast fashion stores". The finding are in line with previous research, which states that shopping is likely to be an exciting activity for women, 
rather than to men. In conformity with the male consumers, the female consumers are likely to feel more independent in shopping. Another point is, the difference between these two genders is that female consumers recognize shopping as a social need, whereas the male consumers pay more attention to the importance of the main product function instead of its secondary function (Plabdaeng, 2015).

Table 3 gender and each option of "the feeling the respondents feel while shopping in fast fashion stores"

\begin{tabular}{lccc}
\hline & Value & df & Asymp. Sig. (2-sided) \\
\hline Pearson Chi-Square & $21.041^{\text {a }}$ & 6 & 0.002 \\
\hline N of Valid Cases & 80 & & \\
\hline
\end{tabular}

This research also found out that there is a significant relationship ( $\mathrm{p}=0.033$ ) between gender and "the importance of the brand's quality" as shown by Table 4. Men tend to purchase items based on its function and how durable the item is, whereas women tend to purchase item based on the image they will get from wearing or using the item. Compared to men, women are more likely to be influenced by family, friends, or sales members Chea (2011). Also stated by Chea (2011), quality is one of the main criteria that men consider when purchasing an item, whereas women put a specific attention to styling, pattern, fabric and colour while selecting a fashion item, (Eckman, Damhorst \& Kadolph, 1990).

Table 4 gender and the importance of the brand's quality

\begin{tabular}{llll}
\hline & Value & df & Asymp. Sig. (2-sided) \\
\hline Pearson Chi-Square & $4.529^{a}$ & 1 & 0.033 \\
\hline N of Valid Cases & 80 & & \\
\hline
\end{tabular}

Each culture has its own norms, values, and specific perceptions. Societal culture, as well as regional subculture and familial values, they are able to affect the formation of an individual's cultural values. This study shows that, there is a significant relationship $(\mathrm{p}=0.025)$ between continent and family, friends' environment influence in purchasing decisions of certain brand as shown in Table 5.

Table 5 continent and family, friends' environment influence in purchasing clothes from certain brand"

\begin{tabular}{lccc}
\hline & Value & df & Asymp. Sig. (2-sided) \\
\hline Pearson Chi-Square & $5.035^{\mathrm{a}}$ & 1 & 0.025 \\
\hline $\mathrm{N}$ of Valid Cases & 80 & & \\
\hline
\end{tabular}

The findings are in line with a previous research from de Mooij and Hofstede (2010). Their research stated that, societal culture, as well as regional subculture and familial values, they are able to affect the formation of an individual's cultural values. Thus, from the beginning of an individual's existence, he/she experiences the benefits and limitations of a particular culture, and those benefits and limitations might become major influences to the consumers' purchasing decisions (de Mooij and Hofstede, 2010).

Table 6 continent and "magazine \& newspaper as the respondents' source of trend and fashion" (Table 6).

\begin{tabular}{lccc}
\hline & Value & df & Asymp. Sig. (2-sided) \\
\hline Pearson Chi-Square & $4.772^{\mathrm{a}}$ & 1 & 0.029 \\
\hline N of Valid Cases & 80 & & \\
\hline
\end{tabular}

The findings can be associated to other findings which show a significant relationship $(\mathrm{p}=0.029)$ between continent and "magazine \& newspaper as the respondents' source of trend and fashion" (Table 6). Luna \& Gupta (2011) stated that the values carried on from the previous generation could further influence the consumer decisions, and affect consumers in deciding which basic everyday products to buy, or which major and important products to buy. Magazine and newspaper are considered as a media to carry certain values and preferences of a culture and social environment to the society. The 
respondents of this study tend to get information about the latest fashion trend from magazine \& newspaper, which shows that they consider the trends that their environment adapts.

\section{Conclusions}

This research has given a new insight of fast fashion industry and consumer behavior in fast fashion industry, especially in Coventry. The hypotheses assumed were proven to be significant. It is found that Coventry University students have their own fast fashion brand's preference, following their friends from the same countries where they came from. Although they have ideas suggested to them from their foreign friends, their preferences still follow their cultures. It is also found that their preferences are split by gender and the preferences each gender chooses also follows the norms of male and female's habits in fashion in their culture. This research contributes in establishing facts that cultural and social factors do influence consumer behavior and purchasing decision in fast fashion industry, especially in Coventry. However, there are still many areas of fast fashion industry that are still not covered in this research, thus further study by other researchers and marketers is suggested.

This research was conducted during summer holiday, so there were less students available at The Hub of Coventry University. There are only 80 questionnaires that were successfully spread and filled in, which is considered as a small number of samples. There were also some respondents who came from the same countries as the previous respondents who already answered the questionnaires, which made the country of origins less variable for this research. In terms of literature review, papers discussing consumer behavior in fast fashion industry are almost rare to find, so it is more difficult to find the gaps that needs to be researched on and it is more difficult to find references that can explain the situation of the findings.

There is not much research available regarding consumer behavior in fast fashion industry or researches regarding factors influencing purchasing decision in fast fashion. General consumer behavior theories are not always applicable in fast fashion industry. It is important for the marketers and other researchers to conduct study to discover the gaps in fast fashion industry and to find other factors that might influence the consumer behavior and purchasing decision in fast fashion industry, in order to know what kind of product they should produce, where to market them, and how to approach the consumers effectively. The right strategy will help the brands to be cost efficient in producing and marketing their products. It is also important to conduct a further research on the style preference and price range desired by consumers coming from different nationalities, so the marketers will be able to determine what kind of product that will cover the satisfaction of consumers in general. When conducting research on this topic, it is suggested to spread questionnaires in the crowded multicultural areas, so participants available are varied and more options are available for the sampling.

There are concerning gaps in the fast-fashion industry at Coventry and several recommendations are offered to close the gaps, such as;

a. Since many consumers in Coventry are students, it is recommended to offer twice-a-month-studentprice for certain hot items from the brands, in order to attract more people.

b. Making an advertisement using materials or models from various countries each time the trend cycle changes, in order to stimulate the costumers from various countries to visit the stores.

c. Better positioning of item for display to attract potential consumers who pass by the stores.

d. Better arrangement of the stores, to avoid the feeling of "stuffiness" for the consumers when they shop. Putting in-style items somewhere visible by the consumers is important.

e. Offer an attractive "in-store fashion styling recommendation session" on a specific day, once a week. This will attract more consumers, because this will provide them an exposure to the brands' products, as well as clear idea on how to wear the clothes, which could stimulate them to buy the clothes. 


\section{References}

Barnes, L. and Lea-Greenwood, G. (2006). Fast Fashion. Bradford, England: Emerald Group Pub.

Bakshi, S. (n.d.). Impact of gender on consumer purchase behavior. Abhinav Journal, 01(09). Retrieved 8 June 2016, from http://www.abhinavjournal.com/images/Commerce_\&_Management/Sep12/1. pdf.

Barnes, L. and Lea-Greenwood, G. (2006). Fast fashioning the supply chain: shaping the research agenda. Journal of Fashion Marketing and Management: An International Journal, 10(3), 259-271.

Bakshi, S. (n.d.). Impact of gender on consumer purchase behavior. Abhinav Journal, 01(09). Retrieved 8 June 2016, from http://www.abhinavjournal.com/images/Commerce_\&_Management/Sep12/1. pdf.

Belleau, B. and Nowlin, K. (2001). Fashion leaders' and followers' attitudes towards exotic leather apparel products. Journal of Fashion Marketing and Management: An International Journal, 5(2),133-144.

Bhardwaj, V. and Fairhurst, A. (2010). Fast fashion: Response to changes in the fashion industry. The International Review of Retail, Distribution and Consumer Research, 20(1), 165-173.

Birtwistle, G. and Freathy, P. (1998). More than just a name above the shop: a comparison of the branding strategies of two UK fashion retailers. Intl J of Retail EDistrib Mgt, 26(8), 318-323.

Boone, L. and Kurtz, D. (1974). Contemporary Marketing. Hinsdale, Ill.: Dryden Press.

Bray, J. (n.d.). Consumer Behaviour Theory: Approaches and Models. Retrieved July 08, 2016, from http://eprints.bournemouth.ac.uk/10107/1/Consumer_Behaviour_Theory_Approaches_\&_Models.p df.

Cachon, G. and Swinney, R. (2011). The value of fast fashion: Quick response, enhanced design, and strategic consumer behaviour. Management Science, 57(4), 778-795.

Chea, P. (n.d.). Gender Differences in the Fashion Consumption and Store Characteristics in Swedish Clothing Store. Retrieved 7 June 2016, from http://bada.hb.se/bitstream/2320/8503/1/2011MF06. pdf.

Christopher, M., Lowson, R. and Peck, H. (2004). Creating agile supply chains in the fashion industry. Intl J of Retail \&Distrib Mgt, 32(8), 367-376.

Crewe, L. and Davenport, E. (1992). The Puppet Show: Changing buyer-supplier relationships within clothing retailing. Transactions of the Institute of British Geographers, 17(2), 183.

Dhurup, M. (2014). The Effects of fashion interest, product novelty and product quality on brand consciousness and brand loyalty in fashion apparel purchase. MJSS.

Durmaz, Y. (2014). The influence of cultural factors on consumer buying behaviour and an application in Turkey. Global Journal of Management and Business Research: E Marketing, 14(01), 01st ser. Retrieved August 09, 2016, from https://globaljournals.org/GJMBR_Volume14/4-The-Influence-of-CulturalFactors-on.pdf.

Hines, J. and Swinker, M. (2001). Knowledge: a variable in evaluating clothing quality. Journal of Consumer Studies and Home Economics, 25(1), 72-76.

Kacen, J. (2000). Girrrl power and boyyy nature: the past, present, and paradisal future of consumer gender identity. Marketing Intelligence \& Planning, 18(6/7), 345-355.

Kaiser, S. and Kaiser, S. (1990). The Social Psychology of Clothing. New York: Macmillan.

Kotler, P. and Armstrong, G. (2006). Principles of Marketing. Upper Saddle River, N.J.: Pearson Prentice Hall.

Lambert, M. (2014, January 12). The lowest cost at any price: The impact of fast fashion on the global fashion industry. Lake Forest College Publications. Retrieved 10 August 2016, from https://publications.lakeforest.edu/cgi/viewcontent.cgi?referer=http://publications.lakeforest.edu/c gi/viewcontent.cgi?article=1038\&context=seniortheses\&httpsredir=1\&article=1038\&context=seniort heses.

Leng, C. and Botelho, D. (2010). How does national culture impact on consumers' decision-making styles? A cross cultural study in Brazil, the United States and Japan. BAR, Braz. Adm. Rev., 7(3). 
Leo, C., Bennett, R. and Härtel, C. (2005). Cross-cultural differences in consumer decision-making styles. Cross-Cultural Management, 12(3), 32-62.

Mitchell, V. and Walsh, G. (2004). Gender differences in German consumer decision-making styles. Journal of Consumer Behaviour, 3(4), 331-346.

Mo, Z. (2015). Internationalization Process of Fast Fashion Retailers: Evidence of H\&M and Zara. IJBM, 10(3).

Mooij, M. D., \& Hofstede, G. (2010). The Hofstede Model: Applications to Global Branding and Advertising Strategy and Research. doi:10.2501/S026504870920104X.

Osorno, S. C. (2014, November 09). Consumer behaviour towards the fashion industry. The fast fashion era. Retrieved 11 August 2016, from https://www.uni-kassel.de/fb07/fileadmin/datas/fb07/5Institute/IBWL/Wagner/EMBS/Correas_Silvia_expose_EMBS.pdf.

Patwardhan, M., Flora, P., \& Gupta, A. (2010). Identification of Secondary Factors that Influence Consumer's Buying Behavior for Soaps and Chocolates. Retrieved August 03, 2016, from http://www.iei.liu.se/fek/svp/mafo/artikelarkiv/1.309573/D5.pdf

Plabdaeng, C. (2010). Gender influence on purchase intention the case study of Thailand. Retrieved 6 June 2016, from https://core.ac.uk/download/files/423/11972775.pdf.

Priest, J., Carter, S., \&Statt, D. A. (2013). Consumer behavior. Retrieved August 06, 2016, from https://www.ebsglobal.net/EBS/media/EBS/PDFs/Consumer-Behaviour-Course-Taster.pdf

Putrevu, S. and Lord, K. (2001). Search dimensions, patterns and segment profiles of grocery shoppers. Journal of Retailing and Consumer Services, 8(3), 127-137.

Rajput, N., Kesharwani, S., \& Khanna, A. (2012). Consumers' attitude towards branded apparels: Gender perspective. IJMS, 4(2).

Rossiter, J. and Foxall, G. (2008). Hull-Spence Behaviour Theory as a paradigm for consumer behaviour. Marketing Theory, 8(2), 123-141.

Solomon, M., Russell-Bennett, R. and Previte, J. (2010). Consumer Behaviour. French Forest, N.S.W.: Pearson.

Solomon, M. (2010). Consumer behaviour. Harlow, Essex: Pearson Prentice Hall

SP, K. (2014). Variables in research. The Indian Journal of Research and Reports in Medical Sciences, 03. Retrieved 15 August 2016 from http://www.ijrrms.com/pdf/2013/jul-sep2013/IJRRMSVol.3 (4)10.pdf.

The Economist. (2005). The future of fast fashion. Retrieved 11 August, 2016, from: http://www.economist.com/node/4086117.

Tokatli, N., Wrigley, N. \& Kizilgün, Ö. (2008). Shifting global supply networks and fast fashion: made in Turkey for Marks \& Spencer. Global Networks, 8(3), 261-280.

Tyler, D., Heeley, J. and Bhamra, T. (2006). Supply chain influences on new product development in fashion clothing. Journal of Fashion Marketing and Management: An International Journal, 10(3), 316328.

Wang, T. Y. (2010). Consumer behavior characteristics in fast fashion. Retrieved 10 July 2016, from http://bada.hb.se/bitstream/2320/7723/2/2010.13.16.pdf.

Wilkie, W. (1986). Consumer Behaviour. New York: Wiley. 